\title{
Functional and syntactic features of free indirect discourse in M.I. Tsvetaeva's prose works
}

\author{
Ruzilya I. Galimullina - Julia K. Kazakova - Olga P. Puchinina
}

DOI: 10.18355/XL.2019.12.03.07

\begin{abstract}
The authors of the article focus their attention on free indirect discourse, a special device to render someone else's speech. We consider the topic under analysis to be of scientific interest due to several factors. Firstly, the study of the problems, associated with the types of rendering someone else's speech is still rather important in modern linguistics, that is, such issues as the author's language, expressive syntax, etc., are reflected in a lot of scientific works. Secondly, the authors consider that despite a great number of serious research on Marina Tsvetaeva's mysterious language in various fields, free indirect discourse in the text field of the poet has not been studied sufficiently, which makes the present study topical. Sentences containing free indirect discourse are classified based on the functional approach to types of sentences, types of the utterance and punctuation.
\end{abstract}

Key words: free indirect discourse, someone else's speech, types of sentences, repetition, punctuation

\section{Introduction}

From our standpoint, the segment of free indirect discourse (hereinafter referred to as FID) in the poet's text field has not been studied sufficiently, which certainly makes this research relevant. Besides, the language of Marina Tsvetaeva's prose and her expressive syntax have always attracted researchers of different fields. After all, "syntax determines the style," as the American researcher Richard Oman put it (Oman, 1959: 82). The purpose of this work is to focus on the syntactic features of arranging free indirect discourse in the prose works by Marina Tsvetaeva (short stories and novels) and to analyze its functioning in the author's text field. The purpose of the research requires solving the following issues: 1) to review the scientific literature on the problem of free indirect discourse, 2) to select and analyze the factual material from the stories and novels of M.I. Tsvetaeva, illustrating the abstract theorems raised in the article.

\section{Discussion}

The authors make a thorough analysis of the syntactic features of FID; according to many scholars (Kus'ko, Bakhtin, Vinogradov, Tarman and Kilınç, 2018; Fludernik, and others), it is a special kind of rendering someone else's speech, possessing a special linguistic potential.

A. Tobler was the first linguist to analyze FID; later, this language phenomenon was studied by P. Kozlovsky and Ch. Bally (Kus'ko, 1980: 8).

A Belorussian researcher of FID E.Ya. Kus'ko singles out four principal theories of FID: 1) The Geneva school of Ch. Bally regarded it as a variant of indirect speech; 2) G. Lerch and his followers regarded FID a variation of direct speech or as a method of its indication in the structure of the author's narrative; 3) According to A. Tobler and P. Kozlovsky, FID is a contamination of direct and indirect speech. Moreover, further theories of FID are based on this concept of "confusion"; 4) A lot of Russian and foreign researchers of FID (such as T. Kalepki, E. Lerkh, E. Lork, E.V. Guliga, Yu.Ya. Nikulikhin, G.M. Chumakov, M.M. Bakhtin, and others) consider it an independent form of rendering someone else's utterance (Kus'ko, 1980: 11). 
O.A. Blinova (2012) notes the pragmatic focus of modern theories of FID, which are based on the work of the Austrian linguist M. Fludernik (1993). The latter writes that only a pragmatic approach can help to understand how the language is arranged. No grammatical description is able to do it, no matter how grammatically exact it might be. The main work, in which a pragmatic approach is outlined, is M. Fludernik's book "The Fictions of Language and the Languages of Fiction" (Fludernik, 1993). Several linguists, G. Redeker (1991, 1995, 1996), B. McHale, Y. Sharvit and others, work in the same key. The advantage of FID over direct and indirect speech, according to M. Fludernik, is its relative "imperceptibility": the reader seldom consciously perceives it in the text as a special technique to render someone else's speech. As a result, FID is usually used to achieve the effect of ambiguity or an inconspicuous change in perspective (Blinova, 2012: 100).

In this paper, we stick to the opinion that FID is the third form of rendering someone else's speech, which occupies an intermediate position between direct and indirect speech. In this respect, we consider Yu.Ya. Nikulikhin's point of view on FID to be quite interesting. He notes that this kind of rendering someone else's speech is independent and believes that in relation to indirect speech, it represents a kind of "step" towards the author's speech (Nikulikhin, 1965: 5).

In Soviet and Russian linguistics, the above-mentioned issues have found a special reflection in the research of V.A. Vinogradov, who believed that FID is a narrative device when the persona's speech is outwardly given in the form of an author's speech and does not have any obvious syntactic or punctuation differences. Thus, the impression is created that the reader is a witness of the persona's actions and words, and imperceptibly penetrates his thoughts (Vinogradov, 1963).

Another outstanding Soviet linguist, M.M. Bakhtin, shared this point of view; speaking about FID, he used the term "another person's reflected word." In his work "Questions of Literature and Aesthetics", he notes that the various combinations of the three syntactic patterns of speech (direct speech, indirect speech, and FID) and various ways of their framing and interlacing with the author's context contribute to a multifaceted "play" of speeches, to their mutual spilling and their reciprocal influence (Bakhtin, 1975:133-134).

When a writer employs FID in his works, he aims at preserving the lexical, phonetic and syntactic features of the internal and external speech of his personas, that is, FID belongs simultaneously to the author's and the persona's plans. Peter Verdonk (2002) writes that FID brings into convergence the perspectives which would conventionally be kept distinct: that of the narrator looking on and that of the inner experience of the character. So, on the one hand, we can sense the presence of an intruding narrator who mediates between the literary character and the reader, whereas on the other hand, we can also detect vestiges of the character's original speech or thought. This doubleedged reading experience may cause ambiguity as to whose voice we are hearing. This gives FID a rich potential for literary effects such as irony (Verdonk 2002: 48).

The peculiarity of FID in Tsvetaeva's prose is the fact that in the studied works Marina herself acts as the protagonist, but in a different time and space, that is, Marina as a child or Marina as a teenager. Consequently, we can consider this speech to be someone else's speech only conditionally, as the narrator and the protagonist are, in fact, the same person. Since most part of the text is represented by thoughts and feelings, which are remote enough for the author, one can say that here we deal with special, Tsvetaeva's "masks": 1) a euphemistic mask; 2) an auto-ironic mask; 3) a language-involving mask; 4) a transgender (character) mask (Voitekhovich and Bykov, 2015).

Secondly, it is time and space that are the most significant substances in the poetry of this intellectual and philosophically profound author. She talks to time, argues with it; she now stops it, trying to run away from it, and now gets in the center of the temporal

XLinguae, Volume 12, Issue 3, June 2019, ISSN 1337-8384, eISSN 2453-711X 
field. For instance, M. Tsvetaeva boldly declares, "Time, I bypass you!" An argument, a conflict with time, being turned towards it, with neglecting it, is one of the major traits of her entire oeuvre. M. Tsvetaeva connects the eternal basis of the world (Danilova, Razzhivin, Salimova, 2014).

\section{Methods.}

Our study is based on 200 examples of FID, continuously sampled from prose texts of Marina Tsvetaeva ("My Pushkin", "Mother and Music", "Father and his Museum", "The Things That Happened", "Chort", "Hlystovki", "The House of Old Pimen", "The Chinese", "The Bridegroom", "The Living Things about the Living Being").

We have concluded that it is typical for M. Tsvetaeva to introduce someone else's speech into the structure of the text without quotes / or without strict paragraph division, i.e., without contrasting the author's speech and the character's FID graphically: But with notes, at first, it did not work at all. You press a key, but a note? The key is here, here it is, black or white, but there is no note, the note is on the line (on which one?). Also, a key is audible, but a note is not. The key is here, but the note is not. So, why is there a note if there is a key? (Tsvetaeva, 1994: 13) (translated by the author - Olga Puchinina). In this passage, containing the uttered FID - the dialogue of Marina and her mother, we do not observe any way of introducing the personas' direct speech (quotes, dashes, or others.)

Another way to reproduce a persona's inner (unuttered) speech is its giving in italics as a part of a sentence or a specific text fragment, i.e., the writer resorts to a graphic means of introducing FID (Arziamova, 2011: 173). I did not understand anything until one day, on the headline of the greeting sheet given me by Augusta Ivanovna for Mother's Glückwunsh, I saw sparrows!, sitting on a musical line instead of notes (Tsvetaeva, 1994: 13). It seems to us that in this example, the word "sparrows" (given by the poet in italics, as if a special sign, and followed by an exclamation mark) was either pronounced by Marina herself in her childhood after her unexpected discovery, or is her inner speech, hence, FID (uttered or unuttered).

We consider of particular interest the following occasional use of the punctuation mark for the introduction of FID, as in the following excerpt from the story "Hlystovki." The Holy Virgin and the Christ were like a domestic disaster, the plague, the fate inherited with the house, because the Kirillovnas in Tarusa had been before us, before all, perhaps even before the Tatars themselves, whose rusty cannon ball (?) we found in the creek (Tsvetaeva, 1994: 94). The question mark, given in brackets, in our opinion belongs to the persona's inner speech and signals some doubt or question that does not even need to be uttered because the answer to it is obvious to the author. Researchers single out the main functional types of sentences containing FID and determine its position in a complex syntactic unit (at the beginning of the paragraph, in the middle of the paragraph, at the end of the paragraph, a separate paragraph) (Kotel'nikova, 2012: 11).

Considering these models, based on the above-mentioned Tsvetaeva's prose works, we distinguish the following types of FID:

1. Phrases, separate words: But I never <...> entered Valera's room without a quick $<\ldots>$ look at the bed: there? (Tsvetaeva, 1994: 50) In this example, one can imagine how mentally the protagonist pronounces the word full of fear, that under the bed, she can see the Devil from her childhood.

2. Simple sentences: The desert was served. Again the blanc-manger. We are always served it on Christmas Eve when we have dinner upstairs in the nursery, and we throw it into the window. However, today is not Christmas Eve! Asya winces wryly, Andryusha pours water on his plate, I sadly ask my mother's permission not to eat it (Tsvetaeva, 1994: 100). We dare to assume that the sentence in bold type is a collective speech of the children, when the dish, unexpected served for dinner, perplexed them all. 


\section{Composite sentences}

3.1. Compound sentences: Oh, how I was going to the sea - this night! (To whom like this since then - when?) But not only I was out for it, and it was approaching me this night - through the blackness of the night: to me alone - with all its essence (Tsvetaeva, 1994: 89). The compound conjunction 'and' accompanied by a dash (the latter being, by the way, the author's favorite punctuation mark) in this case add smoothness and at the same time liveliness to the recollections of the main character. Marina describes her feelings during the long-awaited trip to the sea, the feelings never experienced by her since that.

3.2. Among composite sentences, the author makes most frequent use of complex sentences: <...> I attributed this passion <...> to the eyes. I am not the only one. All poets. (And then they fight duels - that the doll is not passionate!) All poets and Pushkin was the first among them (Tsvetaeva 1994: 69). The complex sentence with an adverbial clause of reason, accompanied by the dash, which is not typical for it, in this case, is used, in our opinion, to intensify the intonational division of this sentence. The dash signals a pause accentuates and foregrounds the sentence, following it. We also feel that the author refers to the circumstances of the duel and the death of the great Russian poet.

3.3. We have found examples of asyndetic composite sentences: It was good for her to <...> "love music." Two musical bloods, paternal and maternal ones, merged into one in her, these two gifted her with what she was like! (Tsvetaeva 1994: 19) In this case, asyndeton is an effective means of adding to FID a deeply emotional, dramatic, and dynamic character, which has always distinguished Marina Tsvetaeva's language persona.

3.4. We note examples of complex syntactic construction, which means a unified part with a syntactic connection of various types: composition, subordination, and possibly, asyndeton): In the morning, on the way to the sea, Valeria said, "Do you feel how it smells? From her-it smells!"

How could one fail to feel it! From here, it smells, and everywhere it smells, but ... the fact of the matter is, that I do not recognize it: the free element did not smell so, and the blue postcard did not smell so (Tsvetaeva, 1994: 89). The cited example contains coordination (From here, it smells, and everywhere it smells; the free element did not smell so, and the blue postcard did not smell so), subordination (but ... the fact of the matter is, that I do not recognize it). Complicated constructions make it possible to compare harmony in nature and the diversity of human relations; besides, lexical repetition, typical for Tsvetaeva (the verb 'smells' is repeated four times), promotes "compressing" the expressiveness of the poet's worldview.

Tsvetaeva's using various kinds of sentences and utterances makes it possible to convey and try to feel the intricate inner world of the protagonist, young Marina, at different stages of her growing-up. We got the impression that when the author portrays herself as a very small girl, the syntactic construction of sentences is simpler than in depicting the thoughts of an older protagonist.

According to the purpose of the utterance among the studied examples of FID, we note: 1) the predominant use of exclamatory sentences. Along with interrogative sentences, they are an excellent means for revealing the complex spiritual world of personas, their internal contradictions, doubts, feelings, and the search for correct solutions. Exclamations in the structure of Tsvetaeva's FID reflect her extremely emotional temperament: The monument to Pushkin was not Pushkin's monument (genitive case), but simply Pushkin's Monument $<\ldots>$ oh, I see these snow-laden shoulders, loaded with all Russian snow, and the strong African shoulders! (Tsvetaeva, 1994: 59).

2) In terms of frequency of use, interrogative sentences take second place in the structure of the analyzed examples of FID. 
Bird of God knows // Neither care nor labor, // It does not hurry // To make a durable nest.

So what does it do then? Moreover, then who makes the nest? Moreover, are there any birds like that, except the cuckoo, which is not a bird, but a huge bird? (Tsvetaeva, 1994: 73) As a child, Marina was curious like any child and showered the people of her immediate circle with questions about what she had heard, seen, or tried to find the answer to these questions herself. In this example, we see that a stanza from A.S. Pushkin's poem "The Gypsies" provoked a whole stream of questions from young Marina.

3) It is peculiar from the scientific point of view that the writer employs declarative sentences very rarely in comparison with other types of sentences. Nevertheless, they sound more dynamic; they convey the features of speech and thought processes of young Marina, experiencing her first love for Alexander Pavlovich, the tutor of his stepbrother: I go to the mirror. The face is round and some stupid. No, I do not look like Tatiana at all, rather like Olga. However, Olga is boring (Tsvetaeva, 1994: 100). On the other hand, it seems that she was too young to feel very strong emotions, so Tsvetaeva prefers to use declarative sentences than exclamatory ones.

According to linguistic observations, the syntactic structure of FID is also characterized by incomplete colloquial structures, elliptical sentences, and paracellular constructions. As a rule, in FID, short structures are correlated with the speech (external or internal) of one person, his internal dialogue with himself. In direct speech, such structures are components of an actual dialogue or polylogue. However, in the elliptical structures in complexes with FID, the emotional content of the rendered someone else's speech is more condensed than in direct speech. In the persona's direct speech, including brief structures, if he knows how to control himself, emotions are often hidden. In this respect, FID is more direct and more emotional. This is expressed graphically in exclamation or question marks at the end of short structures. In direct speech, this is observed much less frequently (Kus'ko, 1980: 136).

However, one blissful day bliss comes to an end. Without waiting for the end of the treatment, under the pretext of high cost of the living (two children in one room, a five-franc pension, millions ...), but in fact, because of Nadya's success $<\ldots>$, A.A. takes the children from Nervi at the seaside to damp "Spasskoye" of the Ilovayskys (Tsvetaeva, 1994: 113). In this excerpt, we observe pronounced FID, containing the main reasons for the move of the protagonist; the author does not consider it necessary to convey the full content of the utterance and presents it only in the form of short structures.

Repetition is one of the characteristic means of syntactic linking in FID (Kus'ko, 1980: 144). Using a number of classifications and definitions of repetition (described, in particular, by I.V. Arnold, V.V. Danilin, Z.P. Kulikova, V.P. Moskvin, and others), in this research we shall use the following working definition of repetition: "Repetition is usually a figure of speech consisting in the reduplication (iteration) of linguistic elements belonging to different linguistic levels, syntactically connected, and contributing to the compositional-semantic organization of the text" (Minakova, 2012: 12). Repetitions strengthen the imagery of the utterance, the writer (poet) consciously deviates from the syntactically unmarked norm, for which a single use of the word is sufficient.

From the position in a sentence, we single out different types of repetitions in the analyzed examples of FID: anaphora, epiphora, framing, anadiplosis, and the repetition of lexemes in the center of the utterance. The analysis showed that Tsvetaeva often resorts to anaphora, i.e., repetition at the start of successive clauses or sentences (19\%): After dinner, 〈...> I received it back (a letter with the love confession-authors' note O.P. and R.G.) with the errors, underlined with a red pencil. It was something to think about. <...> Did Onegin underline mistakes in 
Tatyana's letter? Did Onegin love Raichka? Did he want to take her to the Urals? Did he go to university? Did he have a yellow beard? Did ... Did I look like Tatyana? (Tsvetaeva, 1994: 103)

By repeating the interrogative particle "did," the writer emphasizes the effect of the main character's perplexity. We assume that the girl at the time of her first love expected to receive quite a different answer. Consequently, we deal with an intensifying repetition. Moreover, parallel questions create a rhythmic effect.

Epiphora (epistrophe and antistrophe), i.e., the repetition at the end of successive clauses or sentences, is observed in M. Tsvetaeva's texts rather often (20\%): Why Kirillovnas? <...> At that time I did not think about it, as I did not think about why the ship was called "The Catherine." The Catherine - and that's it. Kirillovnas - and that's it (Tsvetaeva, 1994: 92). In this example, epiphora is the repetition of the simple sentence, 'and that's it,' which strengthens the effect of the protagonist's firm belief that all the women she knows in Tarusa have the same patronymic - Kirillovna. The parallel constructions in the last two sentences and another kind of repetition (anadiplosis), i.e. the repetition of the verb "think about" with a negative particle, serve the same purpose.

Anadiplosis (or catching) is a reduplication of a word, phrase or sentence in two successive units. Thus, anadiplosis connects two ideas, performing rhythmic and expressive functions. In complexes with FID in Tsvetaeva's texts, we often find it rather often (28\%): ... she destroyed all this with a single slip of the tongue: "I love you, - why should I be cunning?" Why should I be cunning? Well, to triumph! Moreover, to triumph - why is that? However, this really does not have a distinct answer for Tatyana, and again she is standing in the enchanted circle of the hall, just as then - in the enchanted circle of the garden - in the enchanted circle of her love loneliness, then - not needed, now - desired, and then and now - loving and unable to be loved (Tsvetaeva, 1994: 72). In our opinion, in this passage, Tsvetaeva has a kind of conversation with A.S. Pushkin, using his quote at the end of the first sentence and catching it at the beginning of the next one. Answering the question, further, she expresses another idea. Moreover, it does not seem enough for her; she resorts to one more repetition of the phrase "in the enchanted circle." Indeed, when reading the whole passage, the reader gets the feeling that the persona has got into a vicious circle, from which there is no way out, only desperation.

Framing is characterized by repeating the same fragment at the beginning and the end of the same sentence or paragraph. We have found out that the writer used this type of repetition occasionally (3\%). Their Hlystovskoe nest was, in fact, the entrance to the town of Tarusa. The last slope - after how many ones?, complete darkness, after so much light (at first it was complete, but here it is green), sudden freshness, after that heat, after dryness was dampness, and, through a bifurcated log, deeply ingrown into the ground, like growing from it, through a cold black loud and fast stream, behind the first willow wattle on the left, invisible behind the willows and the elderberry was “their Hlystovskoe nest" (Tsvetaeva, 1994: 92). The phrase "their Hlystovskoe nest" is repeated at the beginning and the end of the passage; furthermore, in this passage, M. Tsvetaeva repeats the preposition "after" in several partially parallel constructions. These syntactic peculiarities emphasize the poetic and rhythmic effect of the passage.

Synonymous repetition means the use of synonymous means to add a new shade to the utterance, to specify and develop its denotation. In the structure of FID in Tsvetaeva's text field, the synonymous repetition is not often used (5\%). It seemed that Mother buried herself inside us, alive <...> And what happiness it was, that all this was not science, but Lyrics - something that is never enough, twice as little: how little is bread from the whole world to the hungry man, and in the world it is not enough - like radium, the thing which exists in itself is shortage of everything, shortage in itself, <..> which cannot be too much, because it itself is too much, all

XLinguae, Volume 12, Issue 3, June 2019, ISSN 1337-8384, eISSN 2453-711X 
the surplus of yearning and strength, the surplus of strength, replacing yearning, that moves mountains (Tsvetaeva, 1994: 14). This passage contains two cases of synonymous repetition: "little" - "not enough" - "shortage," "too much" - "surplus" against the background of another type of repetition - epiphora ("not enough" and "too little"). Moreover, the expressiveness of the second synonymous repetition "too much" - "surplus" is stressed by using the phonetic repetition - alliteration - of the sound 's'. Such stylistic redundancy, excessive repetition of words and even sounds, serve as a means of emphasis, a special way of expressing the category of intensity.

Another kind of repetition, to which Tsvetaeva resorts occasionally, is ordinary repetition (4\%); using a word twice, she seems to appeal to the reader in a peculiar way and talk to him: One could hear a timid the word "freedom", but also terrible in its timidity, filled with nothing but its own sound. What kind of freedom? Complete. From what? From everything. And, of course, first of all - from home. No, no, not from the parents. The parents were still inviolable, not subject to trial; and besides, did the pressure come from them? (Tsvetaeva, 1994: 116). In the story "The House of the Old Pimen" Marina narrates of her stepsisters' life, the daughters of the famous historian D.I. Ilovaysky, who was especially severe with his children. Tsvetaeva felt with all her heart that the young girls were looking for freedom from the oppressive atmosphere of the house, in which their elder brothers and sisters died one by one. Here one can note one more kind of repetition, characteristic for FIS - root repetition, i.e., the use of cognate words "timid" and "timidity," enriching the meaning of words, extending the meaning of the utterance from individual to general $(8 \%)$.

Another productive form of repetition in FIS is varied repetition (5\%) when a certain element of speech (thought) is supplemented by a modified element. These examples in the complexes with FID are characterized by considerable emotional meaning; they are used to make certain thoughts more prominent. "Through the murk the moon is veering... "< ... "On the sad clearings // Pouring sad light..." Oh, Lord, how sad it is, how twice sad it is, how desperately, hopelessly sad it is, as if imprinted foreverwith sadness, as if with this repetition, Pushkin, sealed the Moon's sadness to the glade (Tsvetaeva, 1994: 79). The root repetition in this example is represented by different parts of speech, that is, not only the same word is repeated, but also cognate lexical units: sad, sadness, and the use of alliterated sound 's' to emphasize the sad picture of the environment.

Further on, we consider it necessary to mention syntactical repetition - parallelism, i.e. the repetition of successive syntactic constructions: sentences, clauses or their parts. Parallel constructions comply with the structure of internal FID, although we have found not very many examples of parallel constructions within the framework of complexes with FID (8\%). Why was not it Seryozha (whom I loved)? <...> Why did I reconcile with his death, accepted it - like everyone else?

But because Seryozha himself accepted it, and Nadia - didn't.

But because Seryozha no longer wanted to live, and Nadya - did.

But because Seryozha was dead, and Nadia wasn't (Tsvetaeva, 1994: 132). This excerpt illustrates that parallel constructions serve the purpose of the rhythmic organization of the text. More than that, in this case, each sentence starts with a new line, which makes the prosaic text look like a piece of poetry, and the synonymous repetition ("accepted it", "no longer wanted to live" and "was dead") stresses the feeling of indifference and detachment of the persona, his lack of desire to live. 


\section{Repetition in M. Tsvetaeva's prose}

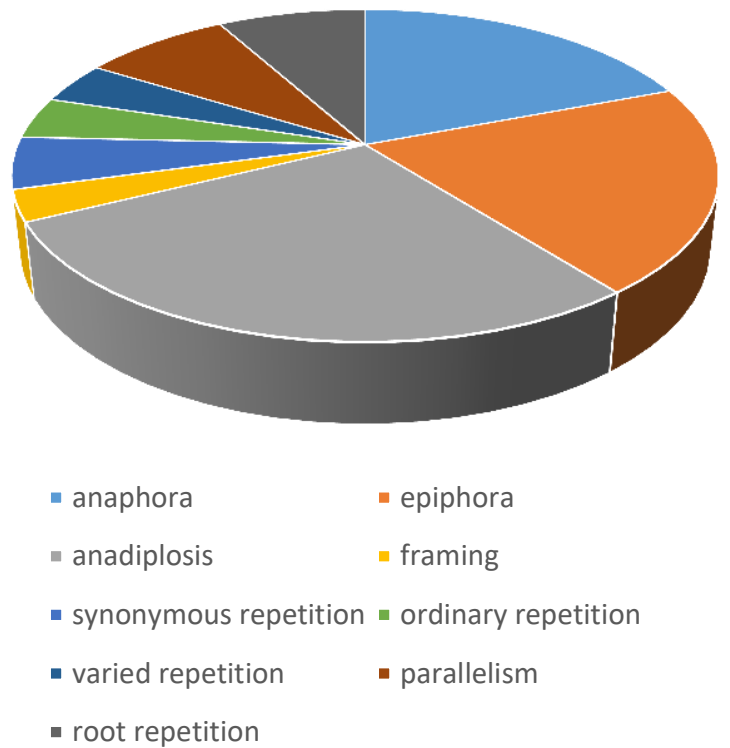

\section{Figure 1: The frequency of using repetition in M. Tsvetaeva's prose}

Also, we have gone into the morphology of the repeated elements, namely, to which parts of the speech they belong. On the material of the illustrative material, we note that repetitions can be represented by different parts of speech: they can be prepositions $(8 \%)$, particles $(10 \%)$, nouns $(14 \%)$, root repetition of different parts of speech (10\%), a combination of two words (18\%), verbs $(20 \%)$, modal words $(6 \%)$, less often - conjunctions (4\%) pronouns (4\%), numerals (2\%), adjectives $(2 \%)$ adverbs $(2 \%)$. 


\section{The morphology of repeated elements}

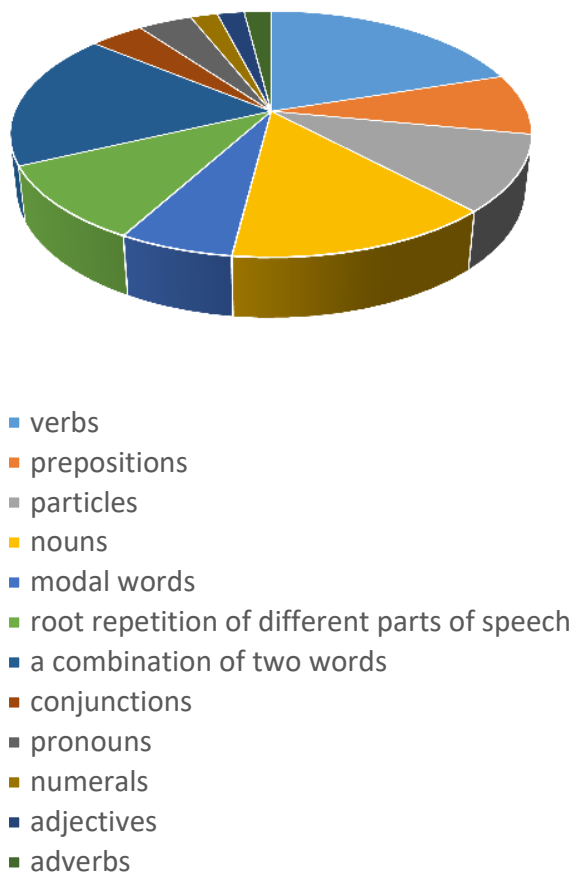

Figure 2: The morphology of repeated elements in M. Tsvetaeva's prose

It should be noted that Tsvetaeva enhances syntactic repetition with phonetic means. Even in her prose, Tsvetaeva remains a poet and uses rhyming words, which gives her texts additional poetic effect. For example, in the following passage, containing incomplete subordinate clauses, united by a repeated conjunction 'because', she uses rhyming nouns 'chromatics', 'grammatics', 'romantics', 'dramatics': Because - I am saying it now - Chromatics is a whole spiritual order, and this system is mine. Because Chromatics is the reverse to grammatics, - Romantics. And Dramatics (Tsvetaeva, 1994: 16).

From the point of view of graphics / punctuation, FID in the analyzed works is presented with the help of the following means:

1. Ellipsis: After dinner, <...> I received it back with the errors, underlined with a red pencil. It was something to think about. <...> Did Onegin underline mistakes in Tatyana's letter? Did Onegin love Raichka? Did he want to take her to the Urals? Did he go to university? Did he have a yellow beard? Did ... Did I look like Tatyana? (Tsvetaeva, 1994: 103) Marina was ready to ask herself another question, but she stopped short, and the ellipsis after the auxiliary verb 'did,' in this case emphasizes the confusion and perplexity of the girl, who did not know what else to think after such a response from the object of her adoration.

2. Exclamation mark: Six black shoes on the white pavement. Two ahead, two walking behind, two closing ones. But it can not last forever! We must come up with something 
(Tsvetaeva, 1994: 170). We feel the exclamation mark stresses the idea that the protagonist was exhausted from a long, monotonous, and endless walk.

3. Question mark: The metronome's click. <...> How do the music ears endure it? (Or do music ears differ from music souls?) (Tsvetaeva, 1994: 20) The question marks in this example reflect the puzzlement of the child, compelled to hear the unpleasant sound of the metronome accompanying her music lessons.

4. Double question mark: Or, it is autumn: Andryusha is scribbling a stick; Asya, sticking out her tongue, is drawing at home; my mother is reading "Eckerhardt"; Valeria is writing a letter to Vera Muromtseva; I'm alone - "playing." (Why?) (Tsvetaeva, 1994: 19) A double question mark strengthens the perplexity (perhaps even indignation) of Marina Ivanovna, who recalled an episode from her childhood when she spent time at the piano at her mother's request.

5. A combination of an interrogative and exclamation marks: <... So, for my own mortal danger, and maybe even - death <...> I should $\langle\ldots\rangle$ hand this money to the “aka-de-mi-cian"? (Tsvetaeva, 1994: 44). In this example, the interrogative and exclamation mark underline how confused the seven-year-old Marina was, before the first confession in the Moscow university church. She was to confess her sins to the priest, her father's acquaintance, the "professor of the academy," and after the ritual, by her parents' order, she had to thank him and give him a ruble. At this time, the girl was strangely keen on the image of the Devil, and this explains the fear she felt before the event.

6. Brackets: $<\ldots>$ my mother $<\ldots>$ answered: "My daughter is only one year old, she is very big and intelligent, I am perfectly happy ..." (God, how she should hate me at that moment, smart and very big because I am not his daughter!) (Tsvetaeva, 1994: 72) The writer suggests what her mother could have felt when she met her first love at the lecture of her husband, Marina Ivanovna's father, and gives this in brackets.

7. Dash: I had - and I's time to say it - no music zeal (Tsvetaeva, 1994: 18). In this example, a dash introduces a parenthetical clause, containing the author's remark about her attitude to music lessons in her childhood.

8. Dash and exclamation mark: But I didn't understand anything, until one day, on the head of the greeting sheet given to me by Augusta Ivanovna for Mother's Glückwunsh, I did not see - sparrows! - sitting on a musical line instead of notes (Tsvetaeva, 1994: 61). Here, with the help of a dash and an exclamation mark, the author underlines what image appeared in the child's imagination and what discovery she made during the lesson.

9. Brackets and a question mark: But most of all ... I loved the violin clef. 〈...〉 (why violin, if I played the piano?) (Tsvetaeva, 1994: 17). The question, given in brackets, could be asked by any child taking a music lesson, not only as inquisitive as Marina was.

10. Brackets and exclamation mark: And, with all the passion of admiration (for admiration is the greatest of passions I have known!) - he kisses him $<\ldots>$ in the forehead (Tsvetaeva, 1994: 179). Marina Tsvetaeva parenthesizes an adverbial clause of the reason (cause), which is a comment of the author on some event in life, and considers it necessary to clarify the use of the phrase "with all the passion of admiration."

As one can notice, in the structure of Tsvetaeva's works under study, FID sometimes takes the form of parenthetical constructions due to the writer's frequent use of brackets and dashes, which are typical for such constructions. I.V. Kotelnikova (2012) notes that parenthetical constructions contain details or comments on events that become the context for the implementation of the persona's FID. They are some kind of associative observations that accompany the literary characters' thinking process, sometimes, a spontaneous one. In this case, parenthetical constructions connect the persona's feelings. Putting parenthetical constructions in the middle of the persona's

XLinguae, Volume 12, Issue 3, June 2019, ISSN 1337-8384, eISSN 2453-711X 
inner speech serves as an indication of semantic and syntactic consistency of these constructions with FID (Kotelnikova, 2012: 163-164). However, in the material under study, we rather often see parenthetical constructions containing the persona's FID, that contributing to the writer's unique style.

Marina Tsvetaeva very often uses the so-called "double" punctuation marks, that is, a combination of a question mark and a dash, a dash and brackets, an exclamation mark and brackets, etc. In our opinion, this excessive use of punctuation marks testifies to the writer's focus on the characters and events described; they emphasize the importance of the situations and feelings, associated with them. The reader can feel that the author is too concentrated on her feelings and mood.

\section{Conclusion}

The analysis of the syntactical (and punctuation) features of the free indirect discourse in Marina Tsvetaeva's text field allows us to conclude the following: 1. M. Tsvetaeva's prose, as is known, is autobiographical; it determines the peculiarity of free indirect discourse in her works, especially in the ways of representing the free indirect discourse (the use of the first person singular instead of the traditional third person singular, the complicated punctuation of complexes with free indirect discourse). These factors let us consider the free indirect discourse under discussion to be someone else's speech only conventionally. In the structure of free indirect discourse, the poet conducts a certain dialogue with herself. The participants of this dialogue are torn apart in time and space. Marina Tsvetaeva speaks to herself (in the past and future): in the emigration (where most of the prose works were written) she misses herself in her homeland, where she was certainly different. Free indirect discourse in M.I. Tsvetaeva's prose acts as the leading means of creating internal dialogues, which in their turn often become a "citation," graphically designed and graphically not designed. 2. The structural patterns of free indirect discoursein the studied works are diverse - from including only one word (and even a punctuation mark) into its structure to complicated syntactic constructions. Such a diverse form of organizing free indirect discourse reflects the intricate inner world of the personas. 3 . Marina Tsvetaeva's prose is represented by various types of sentences, which are often intertwined in various complexes, sometimes occupying a whole paragraph, and it often becomes difficult to determine whom the utterance, in this case, belongs to, the author or the persona. However, the poetics of Marina Tsvetaeva has always been multifaceted and mysterious. 4. In the syntax of M. Tsvetaeva's texts and those containing free indirect discourse, in particular, repetition takes a very important place among its other syntactic features. From the point of view of the structure of repetition in the analyzed examples of free indirect discourse, we note their diverse typology. The poet uses simple repetition and its variations and emphasizes the rhythmic effect due to parallel constructions, there being another type of repetition. 5. We noted that repetitions are represented by different parts of speech: conjunctions, prepositions, particles, nouns, pronouns, adverbs, numerals, word-combination, verbs, and modal words. Besides, to make her prose sound like poems, Tsvetaeva resorts to the phonetic means: alliteration, rhyme, and rhythm. As it can be seen, the syntax of the constructions with free indirect discourse in Marina Tsvetaeva's text field has various functions: intensifying, rhythmic, connecting ones.

\section{Bibliographic references}

ARZIYAMOVA, O.V. 2011. Features of the organization of free indirect speech in Russian contemporary fiction. In: Bulletin of the I. Kant Baltic Federal University, vol. 8, pp. 172-177.

BALLY, CH. 1912. Le style indirect libre en français modern. In: GermanischRomanische Monatschrift, vol. 4, pp. 549-556. 
BAKHTIN, M.M. 1975. The problems of literature and aesthetics. Moscow: Khudozhestvennaya Literatura, $504 \mathrm{p}$.

BLINOVA, O.A. 2012. Free indirect speech in English: the evolution of views in Western linguistics (1912-2012). In: Bulletin of Novosibirsk State University. Series: Linguistics and Intercultural Communication, vol. 10, issue 2, pp. 93-102.

DANOLOVA, J.J. - RAZZHIVIN, A.I. - SALIMOVA, D.A. 2014. The TemporalSpatial Continuum in the Texts of Marina Tsvetaeva and Zinaida Hippius. In: World Applied Sciences Journal, vol. 31, issue 2, pp. 267-271. (ISSN 1818-4952). (C) IDOSI Publications, 2014 DOI: 10.5829/idosi.wasj.2014.31.02.14292.

FLUDERNIK, M. 1993. The fictions of language and the languages of fiction. New York: Routledge, Available online: https://ru.scribd.com/document/75154385/theFictions-of-Language-and-the-Languages-of-Fiction.

KALEPKY, T. 1913. Zum «Style indirect libre» («Verschleierte Rede»). In: Germanisch-Romanische Monatschrift, vol. 5, pp. 608-619.

KOTELNOKOVA, I. V. 2012. Linking function of parenthetic constructions in free indirect speech. In: Izvestiya of Southern Federal University. Philological Sciences. Rostov-on-Don, vol. 2, pp. 162-169.

KUS'KO, E.Y. 1980. The language problems of the contemporary fiction. Represented speech in the literature of the GDR. Lvov: Vusshaya Schola. p. 208.

LERCH, E. 1914. Die stilistische Bedeutung des Imperfektums der Rede «style indirect libre». In: Germanisch-Romanische Monatschrift, vol. 6, pp. 470-489.

MINAKOVA, A. A. 2012. Types and functions of repetitions in the poetic texts of Evgeny Evtushenko: Thesis Abstract ... Candidate of Philology. Maikop, 22 p.

NIKULIKHIN, Yu.Ya. 1965. Functions and synonyms of the conditional mood in modern German: Thesis Abstract ... Candidate of Philology. Moscow, 23 p.

OHMANN, R. 1959. Prolegomena to the Analysis of Prose Style: Style in Prose Fiction. New York, $82 \mathrm{p}$.

TARMAN, B. - KILINÇ, E. 2018. Poetry in the Social Studies Textbooks in Turkey. Journal of Culture and Values in Education, 1(1), 50-62. Available online: http://cultureandvalues.org/index.php/JCV/article/view/4

TOBLER, A. 1887. Vermischte Beitrage zur französischen Grammatik. In: Zeitschrift fur romanische Philologie, vol. 11, pp. 67-74.

TSVETAEVA, M. 1994. Collected works: In 7 vol. Vol. 5: Autobiographical prose. Articles. Essay. Translations. Moscow: Ellis Luck, 720 p. ISBN 5-7195-0016-2.

VERDONK, P. 2002. Stylistics. Oxford University Press, p. 124. ISBN 0-19-4372405 .

VINOGRADOV, V.A. 1965. Free indirect discourse Available online: http://philologos.narod.ru/tamar/t12.htm (accessed: 19.03.2018).

VOITEKHOVICH, R.S. - BYKOV, A.V. 2015. Types of masks in Marina Tsvetaeva's poetry. In: European Journal of Science and Theology, vol. 11, issue 5, pp. 119-128.

ZHILINA, I.S. 2015. Functional semantics and the features of structural and grammatical organization of free indirect discourse in English, German and Russian (on the material of fiction): Thesis Abstract ... Candidate of Philology. Moscow, $22 \mathrm{p}$.

Words: 6668

Characters: 41872 (23,26 standard pages)

Ruzilya I. Galimullina

Department of Foreign Languages and Professional Communication

The Institute of Management, Economics and Finance of Kazan Federal (Volga Region) University

Address 4, Butlerova Street, Kazan, 420012, Russia 
ruzilya.vahitova@mail.ru

associate professor Julia K.Kazakova, Ph.D.

Department of Foreign Languages

Elabuga Institute (Branch) of Kazan Federal (Volga Region) University

Address 89, Kazanskaya Street, Elabuga, 423600,

Russia

kazakova696@gmail.com

assistant professor Olga P. Puchinina

Department of Foreign Languages

Elabuga Institute (Branch) of Kazan Federal (Volga Region) University

Address 89, Kazanskaya Street, Elabuga, 423600,

Russia

olga.puchinina@gmail.com 